\title{
Serving Culturally and Linguistically Diverse Clients: A Review of Changing Trends in Speech-Language Pathologists' Self-efficacy and Implications for Stakeholders
}

\author{
Siva Priya Santhanam', Sabiha Parveen²
}

${ }^{1}$ Department of Communication, Arts, \& Sciences, Metropolitan State University of Denver, Denver, CO; ${ }^{2}$ Department of Communication Sciences and Disorders, Oklahoma State University, Stillwater, OK, USA

\begin{abstract}
With the rapid rise in our culturally and linguistically diverse (CLD) clientele, it is essential to understand the clinical self-efficacy of speech-language pathologists (SLPs) serving these clients and to examine the efforts we have taken as a field to better prepare our future clinicians. Studies from the past 25 years that examine SLPs' clinical self-efficacy in CLD service delivery were located using electronic databases and manual searchers. A total of 13 articles were identified. A review of the existing studies indicated that reports on clinical self-efficacy among SLPS working with CLD clients has not markedly improved during the last two decades. Nevertheless, there is a positive trend in two areas: (1) the availability and access to training and resources for SLPs, and (2) the willingness to work with more CLD clients. Factors that are barriers to bilingual service delivery still need to be addressed. Future implications for stakeholders are discussed.
\end{abstract}

Keywords: Bilinguals, Challenges, Clinical self-efficacy, Cultural and linguistic diversity, Speech-language pathologist

\section{INTRODUCTION}

The cultural and linguistic landscape of the United States has been changing rapidly in the last three decades. According to the U.S. Census Bureau, 21.1\% (60.3 million) of the population in the United States speak a language other than English at home [1]. It is expected that these numbers would increase to about $43 \%$ by the year 2020 [2]. Correspondingly, speech-language pathologists (SLPs) in the United States are seeing a rise in their caseload of culturally and linguistically diverse (CLD) clients [3]. SLPs are often faced with clients who speak a language or belong to a culture different from their own. Kritikos [4] reported that 95\% of SLPs serve at least one client from a CLD background. Yet, a vast majority of SLPs in the United States are monolingual English speakers. There continues to be a stark minority of bilingual SLPs [5] and a mismatch between the proportion of CLD clients and the available proportion of bilingual service providers. Only 6.5\% of American Speech-Language-Hearing Association (ASHA) members identify themselves as bilingual service providers. Spanish-English bilingual SLPs con-

\section{Q \\ Check for
updates

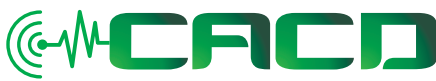 \\ Received: September 5, 2018 \\ Revision: December 12, 2018 \\ Accepted: December 19, 2018 \\ Correspondence: \\ Sabiha Parveen \\ Department of Communication Sciences and Disorders, Oklahoma State \\ University, 042 Murray Hall, Stillwater, OK 74078, USA \\ Tel: +405-744-5116 \\ Fax: +405-744-8070 \\ E-mail: sabiha.parveen@okstate.edu}

(C) 2018 The Korean Association of SpeechLanguage Pathologists

This is an Open Access article distributed under the terms of the Creative Commons Attribution NonCommercial License (http://creativecommons.org/ licenses/by-nc/4.0/) which permits unrestricted noncommercial use, distribution, and reproduction in any medium, provided the original work is properly cited. 
stitute $4.41 \%$ of the overall bilingual service providers and an even lesser percentage (2.09\%) of bilingual SLPs speak languages other than Spanish [6]. Figure 1 shows the demographics of bilingual service providers in the United States. Even among our bilingual service providers, there exist differences in ethnicity, culture, and second language use. The rapid change in client demographics and language discordance between service providers and clients has mandated an increase in the number of SLPs, both monolingual and bilingual, with the necessary knowledge and preparedness to serve CLD clients. We not only have a need for skilled service providers, but those who possess the self-efficacy to work with clients from diverse linguistic and cultural backgrounds.

Clinical self-efficacy is an important construct that has been known to impact clinical outcomes $[7,8]$. Self-efficacy is defined as an individual's perception of "how well one can execute a course of action required to deal with prospective situations" [9]. Bandura explains self-efficacy as an individual's sense of confidence to perform a task; it involves an individual's initiation of coping behaviors when task complexity increases; and the ability to withstand the task despite performance-related challenges [10]. For the purpose of this article, we define self-efficacy as a clinician's perception of how confident, comfortable, and competent they feel to create change in clients' communication. Bandura noted that outcome plays an important role in shaping one's sense of self-efficacy; previous successes and achievements strongly influence self-efficacy [11]. When practice challenges increase, individuals feel less confident in their ability to create change in behavior [12], and thereby have low self-efficacy. To date, most SLPs working with clients from CLD backgrounds are faced with several difficulties including increased physical effort, emotional,

$\square$ Total no. of certified SLPs \& audiologists $\square$ Spanish-English bilingual SLPs

$\square$ Bilingual SLPs who speak languages other than spanish

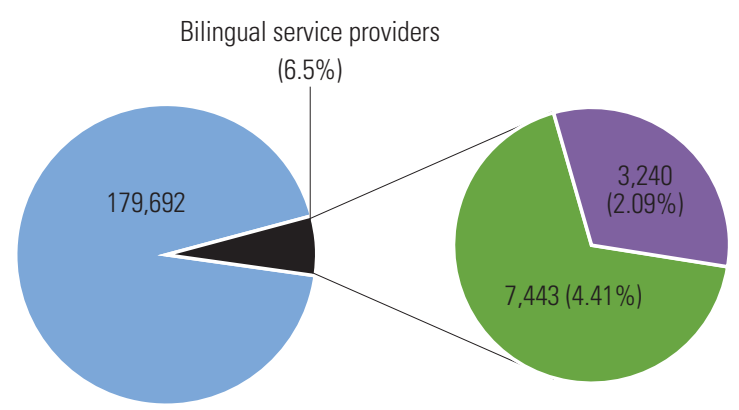

Figure 1. Demographics of bilingual service providers (ASHA, 2017). cognitive, and information processing challenges in the absence of limited relevant cultural and linguistic support and training [3]. It is highly likely that such a complex work scenario can lead to a sense of reduced self-efficacy, diminished motivation, and in turn low quality of clinical services.

Early research on self-efficacy in teachers has shown that teachers who report a high sense of self-efficacy see superior success rates among their students [13]; they are open to experimenting novel ideas [14], and they tend to persist during challenging classroom situations [15]. More recently, self-efficacy has been studied extensively in the field of nursing. For example, Mazhari investigated the relationship between clinical self-efficacy and creativity among 60 nursing students [7]. The author found that increased self-efficacy was associated with increased creativity and better willingness to problemsolve in novel scenarios. Similarly, Song \& Yang [16] reported a significant correlation between nursing students' clinical self-efficacy and their satisfaction in clinical practice and selfdirected learning.

In the last two decades, researchers in our discipline have tried to understand the self-efficacy, challenges, and experiences of SLPs working with clients from CLD backgrounds [4, 17]. These research initiatives have propelled ASHA to provide specialized and increased support on CLD service delivery. Consequently, ASHA has been actively creating more educational resources, supporting research endeavors, and facilitating university programs to prepare a skilled next generation of SLPs.

In this narrative review, we aim at understanding and synthesizing existing research evidence on clinical self-efficacy and barriers to service delivery among SLPs working with CLD clients. We do not present a critical review or systematic review of specific assessment and/or intervention studies. Instead, we provide an overall perspective of clinical self-efficacy among SLPs highlighting changing trends in access to resources and persisting barriers to service provision. The goals of this review, therefore, are two-fold: (1) to summarize research findings on clinical self-efficacy among SLPs working with CLD populations, and (2) to identify priorities for future research and directions in CLD service delivery.

\section{METHODS}

In considering a narrative review on self-efficacy in SLPs, we conducted a thorough review of the literature. Figure 2 shows the steps involved in the article search process. The keywords 


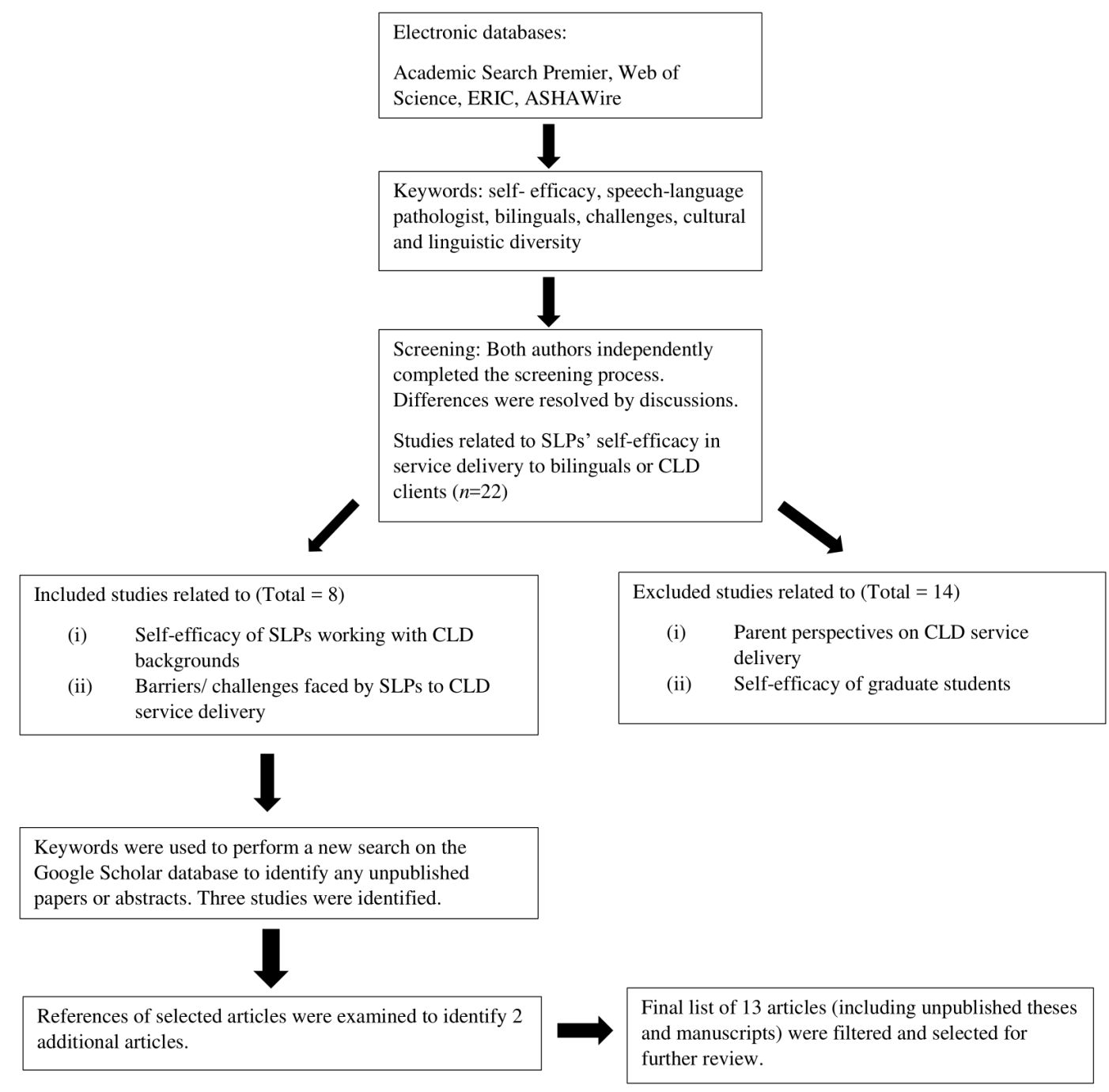

Figure 2. Flowchart describing the screening and identification of relevant articles has been attached as a tiff file along with the manuscript.

were selected based on the purpose of the review. Articles that did not meet the purpose were filtered, and a final list of 13 articles (including the authors' unpublished survey study) was identified. Table 1 provides a summary of these investigations. All except two articles used a survey methodology. Kadyamusuma reviewed SLPs' barriers to CLD service delivery [5] and Perry provided a review of the current state of confidence among SLPs to work with CLD clients [18].

\section{RESULTS AND DISCUSSION}

\section{Self-efficacy among SLPs working with CLD populations}

In general, studies in the past and anecdotal evidences indicate that both monolingual and bilingual SLPs feel inadequately equipped to support the unique needs of clients that speak a language different from theirs $[4,17,19]$. According to the ASHA's schools survey report, only $8 \%$ of the school-based SLPs rated themselves as very qualified while addressing CLD issues in service delivery [20]. Most investigations in the past that focused on understanding SLPs' self-efficacy in serving CLD clients used a survey methodology to gather data. While some investigations focused on specific regions within the United States [3], other surveys garnered nation-wide data [21] as shown in Table 1. Roseberry-McKibbin \& Eicholtz [17] were among the very first researchers who set out to understand self-efficacy among SLPs serving CLD populations. They conducted a national survey of SLPs working with English language learners in public schools. Results of this investigation revealed that SLPs indicated a strong need for continued education in assessing and treating clients with limited English 
Table 1. Summary of studies that examined SLPs' self-efficacy and barriers to CLD service delivery

\begin{tabular}{|c|c|c|c|c|c|}
\hline Authors & Clinical setting(s) & Sample size & $\begin{array}{l}\text { Data collection } \\
\text { areas }\end{array}$ & Study design & Research focus \\
\hline $\begin{array}{l}\text { Roseberry-McKibbin \& } \\
\text { Eicholtz (1994) }\end{array}$ & Schools & 1,145 SLPS & United States & Survey & $\begin{array}{l}\text { Gathered information in several major areas relating to } \\
\text { services provided for CLD children. }\end{array}$ \\
\hline $\begin{array}{l}\text { Young \& Westernoff } \\
\text { (1999) }\end{array}$ & $\begin{array}{l}\text { Ontario Speech-Language } \\
\text { Pathologists and } \\
\text { Audiologists Conferences } \\
1996\end{array}$ & Unavailable & Canada & Survey & Identified shared issues and challenges in work settings \\
\hline $\begin{array}{l}\text { Roseberry-McKibbin, } \\
\text { Brice, O'Hanlan } \\
\text { (2005) }\end{array}$ & Schools & 1,736 SLPS & United States & Survey & $\begin{array}{l}\text { (a) Conducted an in-depth analysis of the survey results in } \\
\text { terms of relationships between variables in respondents' } \\
\text { backgrounds and perceived problems in providing service } \\
\text { delivery to ELL students. } \\
\text { (b) Compared answers from the } 1990 \text { and } 2001 \text { surveys in } \\
\text { terms of similarities and differences }\end{array}$ \\
\hline Kritikos (2003) & Schools \& Private Practice & 811 SLPS & $\begin{array}{l}\text { United States } \\
\text { (divided into } 6 \\
\text { regions) }\end{array}$ & Survey & $\begin{array}{l}\text { (a) Compared difference between mono- and bilingual SLPS } \\
\text { on personal self-efficacy in assessing CLD clients } \\
\text { (b) Compared difference between mono- and bilingual SLPs } \\
\text { on general self-efficacy in assessing CLD clients } \\
\text { (c) Compared difference between mono- and bilingual SLPS } \\
\text { on how likely they are to recommend language } \\
\text { intervention services to CLD children }\end{array}$ \\
\hline Harris (2004) & Schools & 230 SLPS & Florida & $\begin{array}{l}\text { Mixed-methods } \\
\text { design; Survey } \\
\text { and semi- } \\
\text { structured } \\
\text { interviews }\end{array}$ & $\begin{array}{l}\text { (a) Discussed beliefs about the language assessment of } \\
\text { bilingual/bicultural/bidialectal students, } \\
\text { (b) Discussed professional efficacy beliefs (both personal } \\
\text { and general) as they relate to assessing the language } \\
\text { skills of bilingual/bicultural/bidialectal students, and } \\
\text { (c) Reported supports and barriers to assessing the language } \\
\text { skills of bilingual/bicultural/bidialectal students }\end{array}$ \\
\hline $\begin{array}{l}\text { Kohnert, Kennedy, } \\
\text { Glaze, Kan, \& Carney } \\
\text { (2003) }\end{array}$ & Schools & 104 SLPS & Minnesota & Survey design & $\begin{array}{l}\text { (a) Determined if, and how, recent changes in the overall } \\
\text { state demographics were reflected on caseloads of SLPS } \\
\text { (b) Identified challenges clinicians faced in meeting the } \\
\text { needs of an increasingly diverse population }\end{array}$ \\
\hline Hammer (2004) & Schools & 213 SLPS & $\begin{array}{l}\text { Participants } \\
\text { represented } 41 \\
\text { states }\end{array}$ & Survey design & $\begin{array}{l}\text { Compared differences in confidence of SLPs between urban } \\
\text { and rural SLPs based on training received. }\end{array}$ \\
\hline Roberts (2008) & Schools & 4 SLPS & New York & $\begin{array}{l}\text { Qualitative } \\
\text { design; semi- } \\
\text { structured } \\
\text { interviews }\end{array}$ & $\begin{array}{l}\text { (a) Discussed perceived challenges of SLPs in bilingual } \\
\text { service delivery and } \\
\text { (b) Possible solutions to address challenges }\end{array}$ \\
\hline $\begin{array}{l}\text { Guiberson \& Atkins } \\
\text { (2012) }\end{array}$ & $\begin{array}{l}\text { Schools, universities, early } \\
\text { intervention teams, \& } \\
\text { private practice }\end{array}$ & 154 SLPS & Colorado & Survey design & $\begin{array}{l}\text { (a) Examined diversity training received by SLPs; and } \\
\text { (b) SLPs' professional perspectives on serving CLD } \\
\text { populations including confidence, practices, and } \\
\text { challenges reported }\end{array}$ \\
\hline Kimble (2013) & $\begin{array}{l}\text { SLPs who attended ASHA } \\
\text { Schools Conferences \& } \\
\text { Missouri Speech- } \\
\text { Language-Hearing } \\
\text { Association Conferences, } \\
2009\end{array}$ & 192 SLPS & $\begin{array}{l}\text { United States \& } \\
\text { Guam }\end{array}$ & Survey design & $\begin{array}{l}\text { (a) Investigated comfort levels in providing service delivery } \\
\text { to ELL/LEP students } \\
\text { (b) Determined if service delivery comfort levels reflected } \\
\text { professional development in working with ELL/LEP } \\
\text { students }\end{array}$ \\
\hline $\begin{array}{l}\text { Santhanam \& Parveen } \\
\text { (2017) }\end{array}$ & $\begin{array}{l}\text { Schools, private practice, } \\
\text { universities, nursing } \\
\text { homes, hospitals, early } \\
\text { intervention settings }\end{array}$ & 337 SLPS & United States & Survey design & $\begin{array}{l}\text { (a) Examined if there is an increase in number of SLPS } \\
\text { reporting improved self-efficacy compared to prior studies. } \\
\text { (b) Compared difference between self-efficacy of } \\
\text { monolingual and bilingual SLPs } \\
\text { (c) Examined if work settings (pediatric or adult) impact } \\
\text { SLPs' self-efficacy }\end{array}$ \\
\hline
\end{tabular}


proficiency. Further, although participant-SLPs were interested in learning about CLD service delivery, most of them were reluctant to take up English-language learners (ELL) in their caseload due to reduced confidence in dealing with challenges. After a decade, Roseberry-McKibbin [21] replicated the national survey of school-based SLPs working with ELL clients to understand the similarities and differences between their investigations in 1990 and 2001. With approximately 300 additional participants than their preliminary investigation, results of this study demonstrated an increased confidence in serving ELL clients among SLPs in the west and southwest regions of the United States.

In a different study, Kohnert and colleagues explored the depth and breadth of the diverse population in Minnesota through a web-based survey [22]. Thirty nine percent of their respondents reported having limited competency in assessing bilingual clients, and found several challenges in bilingual clinical practice. Around the same time, Kritikos conducted a survey to understand if bilingual SLPs differed from monolingual SLPs in their personal and general efficacy of assessing bilingual/bicultural clients. She defined personal self-efficacy as an individual's ability to change the clients' learning and behavior, and general efficacy as an individual's belief about a field's ability to change the clients' learning and behavior [4]. Kritikos found that a majority of the respondents reported low personal self-efficacy (85\%) and general efficacy (96\%) while assessing language in CLD clients even with an interpreter who spoke the clients' primary language [4]. Further, these participants reported a tendency to under refer or over refer CLD clients due to insufficient knowledge and decision-making in assessment and referral of clients for intervention. Harris, through a mixed-method design, investigated the self-efficacy beliefs of 1,127 school-based SLPs assessing language in bilingual clients. Quantitative data revealed that most SLPs were "somewhat competent" in assessing bilingual clients. In addition, qualitative results revealed that SLPs from different racial and ethnic backgrounds had an increased sense of personal self-efficacy when compared to SLPs from mainstream cultures. Participant SLPs attributed this increased sense of competence to three reasons: (1) their personal experiences living in a diverse background, (2) knowledge and awareness of their limitations in working with CLD clients, and (3) their willingness to seek out assistance when needed.

More recently, some positive changes in the overall sense of clinical self-efficacy among SLPs were reported by Guiberson and Atkins [3]. These authors were interested in learning how
SLPs have progressed in their service delivery to CLD clients since the 1990s. The researchers obtained survey data from 154 SLPs in Colorado. While $70 \%$ of them were comfortable assessing and treating clients from other cultures, they were less comfortable in working with clients who spoke a language other than English indicating a strong need for continued training in that area. Additionally, participants reported a decrease in use of English standardized assessments for linguistically different clients, and reduction in use of family members as language interpreters. In contrast to previous investigations that focused on SLPs in specific work settings or geographical regions of the United States, Santhanam \& Parveen [23] conducted a nation-wide survey to investigate the clinical self-efficacy of SLPs working in a variety of settings. Results revealed that $49.8 \%$ of bilingual SLPs and $37.1 \%$ of monolingual SLPs reported that they felt competent in their assessment of linguistically diverse clients. Similarly, $47.4 \%$ of bilingual and 49.2\% of monolingual SLPs reported competency in providing intervention. In contrast to these findings, all SLPs reported competency in assessing English-speaking clients, and 98.2\% of monolingual SLPs and $92 \%$ of bilingual SLPs reported competency in providing intervention for English-speaking clients.

In summary, based on the available research evidence in the past two decades, some inferences can be made. First, reports on clinical self-efficacy among SLPs working with CLD clients has not markedly improved during the last two decades. A large majority of practicing SLPs continue to report limited competency while working with clients from diverse backgrounds. Nevertheless, several positive changes in CLD service delivery have been reported. For example, there seems to be an increase in the number of SLPs working with and indicating a willingness to serve CLD clients [21]. This rise could be attributed to the heightened diversity in our client population and/or the increased need for working with CLD clients. Additionally, there is an increased understanding and awareness among SLPs to better prepare themselves to face diverse clientele. More and more service providers indicate the need to educate themselves on working with CLD clients [4]. Despite these positive changes, several factors continue to act as challenges to service delivery impacting SLPs' overall sense of self-efficacy. In the subsequent section, we elaborate on the barriers and challenges that face SLPs in working with clients from diverse backgrounds.

\section{Barriers to service delivery}

Multiple aspects of bilingual/bicultural service delivery and 
Table 2. Summary of challenges as reported in previous literature

\begin{tabular}{|c|c|c|}
\hline Challenges reported by SLPs in CLD service delivery & $\begin{array}{l}\text { No. of } \\
\text { studies }\end{array}$ & List of studies that reported challenges \\
\hline Lack of knowledge on client's primary language & 5 & $\begin{array}{l}\text { Roseberry-McKibbin \& Eicholtz (1994); Young \& Westernoff (1999); } \\
\text { Kohnert et al. (2003); Kritikos (2003); Roseberry-McKibbin et al. (2005) }\end{array}$ \\
\hline Lack of knowledge of client's culture and home environment & 5 & $\begin{array}{l}\text { Roseberry-McKibbin \& Eicholtz (1994); Young \& Westernoff (1999); } \\
\text { Kritikos (2003); Roseberry-McKibbin et al. (2005); Roberts (2008); } \\
\text { Santhanam \& Parveen (2017); Kadyamusuma (2016) }\end{array}$ \\
\hline Lack of knowledge of developmental norms in client's primary language & 4 & $\begin{array}{l}\text { Roseberry-McKibbin \& Eicholtz (1994); Kohnert et al. (2003); Roseberry- } \\
\text { McKibbin et al. (2005); Kadyamusuma (2016) }\end{array}$ \\
\hline Lack of normative data for CLD clients & 2 & Kritikos (2003); Guiberson \& Atkins (2012) \\
\hline Lack of less biased assessment instruments & 6 & $\begin{array}{l}\text { Roseberry-McKibbin \& Eicholtz (1994); Young \& Westernoff (1999); } \\
\text { Kohnert et al. (2003); Roseberry-McKibbin et al. (2005); Guiberson \& } \\
\text { Atkins (2012); Santhanam \& Parveen (2017) }\end{array}$ \\
\hline Lack of appropriate intervention materials & 2 & Young \& Westernoff (1999); Kohnert et al. (2003) \\
\hline $\begin{array}{l}\text { Lack of knowledge about the nature of second language acquisition and } \\
\text { phenomenon of bilingualism }\end{array}$ & 2 & $\begin{array}{l}\text { Roseberry-McKibbin \& Eicholtz (1994); Roseberry-McKibbin et al. } \\
\text { (2005) }\end{array}$ \\
\hline $\begin{array}{l}\text { Challenges in assessing clients who spoke a language other than } \\
\text { English }\end{array}$ & 2 & Roberts (2008); Kadyamusuma (2016) \\
\hline Challenges in providing intervention to bilingual clients & 2 & Roberts (2008); Kadyamusuma (2016) \\
\hline $\begin{array}{l}\text { Difficulty distinguishing between language difference and language } \\
\text { disorder }\end{array}$ & 2 & $\begin{array}{l}\text { Roseberry-McKibbin \& Eicholtz (1994); Roseberry-McKibbin et al. } \\
\text { (2005) }\end{array}$ \\
\hline $\begin{array}{l}\text { Lack of knowledge regarding when to refer the CLD client for } \\
\text { intervention or a tendency to over-refer CLD clients }\end{array}$ & 1 & Kritikos (2003) \\
\hline $\begin{array}{l}\text { Lack of interpreters especially in rural areas or regions with limited } \\
\text { cultural or linguistic diversity }\end{array}$ & 6 & $\begin{array}{l}\text { Roseberry-McKibbin \& Eicholtz (1994); Kritikos (2003); Roseberry- } \\
\text { McKibbin et al. (2005); Guiberson \& Atkins (2012); Parveen \& } \\
\text { Santhanam (2015); Kadyamusuma (2016) }\end{array}$ \\
\hline $\begin{array}{l}\text { Miscommunications while working with interpreters and difficulties } \\
\text { collaborating with them }\end{array}$ & 3 & Kritikos (2003); Guiberson \& Atkins (2012); Santhanam \& Parveen (2017) \\
\hline $\begin{array}{l}\text { Interpreters do not always possess vocabulary/terminology relevant to } \\
\text { the field }\end{array}$ & 1 & Kadyamusuma (2016) \\
\hline $\begin{array}{l}\text { Challenges in locating and receiving quality education in multicultural/ } \\
\text { bilingual issues }\end{array}$ & 1 & Roberts (2008) \\
\hline Limited family resources & 1 & Kohnert et al. (2003) \\
\hline $\begin{array}{l}\text { Difficulty collaborating with family members and understanding their } \\
\text { beliefs }\end{array}$ & 1 & Kadyamusuma (2016) \\
\hline Lack of allied professionals who speak client's primary language & 3 & $\begin{array}{l}\text { Roseberry-McKibbin \& Eicholtz (1994); Kohnert et al. (2003); Roseberry- } \\
\text { McKibbin et al. (2005) }\end{array}$ \\
\hline Limited carryover from school to home for all languages & 1 & Santhanam \& Parveen (2017) \\
\hline Need for more bilingual SLPS & 3 & Kritikos (2003); Roberts (2008); Kadyamusuma (2016) \\
\hline $\begin{array}{l}\text { SLPs are sometimes not aware of their own culture and how it can } \\
\text { impact their service delivery }\end{array}$ & 1 & Kadyamusuma (2016) \\
\hline
\end{tabular}

factors related to both service providers and clients add to its complexity [5]. Intrinsic factors such as limited knowledge of the client's culture, and limited understanding of cognitive and language developmental norms of clients' primary lan- guage have been reported [4]. Additionally, lack of language interpreters and the need for appropriate assessments act as extrinsic factors that impact SLPs' clinical self-efficacy [24]. Table 2 includes a summary of challenges reported by SLPs in 
CLD service delivery. Findings from seven previous surveybased investigations and one review article [5] were garnered. Several inferences can be made based on the summary in Table 2. While some reported challenges have been highly similar among the studies, earlier investigations $[4,17]$ reported more number and type of practice challenges when compared to those reported by later studies [23]. Perhaps, these challenges have reduced over time with the increase in availability and access to resources and supports [25]. The earlier investigations showed that SLPs had perceived difficulties in differentiating a language disorder from a difference. However, later studies did not report that challenge. Further, the lack of appropriate assessment tools continues to be a persisting challenge.

A wide range of factors related to CLD clients act as additional barriers. Bilingual/bicultural families differ not only in their primary language and cultural beliefs, but also in their intervention priorities [26], parenting styles [27], disciplining methods [28], and availability of support systems [29]. For example, Mexican and Mexican-American families rely heavily on their extended family for social, emotional, and financial support [30]. Even families that share the service provider's primary language, demonstrate differences in their dialects, choice of language used at home versus other social settings (school, work, etc.), length of exposure to each language, and age of immigration [31]. Some CLD clients and their family members have limited understanding of the purpose and nature of language assessments [32]. Several families also differ in their understanding of what constitutes a disability, perceived helpfulness of intervention and bilingual services, and reactions to diagnosis [33]. Persisting challenges in working with CLD clients, however, indicates that the available education, training, and supports continue to be less than ideal despite efforts to increase graduate coursework, research, and clinical practicum.

\section{Changing trends in education and preparation of SLPs}

There is a rise in the availability and access to pre-service (coursework and practicum completed in graduate school) and in-service (ongoing on-the-job continued education, workshops, and professional collaborations) opportunities for practicing SLPs [3]. In 2000, less than one-third of the accredited graduate programs in the United States offered courses relevant to service delivery in CLD populations [22]. As of 2014, ASHA's accreditation standards for graduate education programs in audiology and speech-language pathology re- quire that all students have academic and clinical practicum opportunities aimed at serving CLD clients [34]. In addition, students understand their own cultural background and the impact of the client's cultural background on clinical practice [35]. Several universities across the nation offer bilingual emphasis programs and bilingual competency certificate for their students. For example, Arizona State University, New Mexico State University, and University of Texas at Austin offer specialized programs on CLD service delivery. More recently, members of the faculty and researchers at the North Carolina Central University developed a unique framework for their graduate program in which cultural competence is infused at all levels of their graduate curriculum [36]. In this model, students receive several specialized opportunities to work with CLD clients in a variety of settings including clinical practicum hours and international service learning experiences.

Since the early 1980s, ASHA has been taking initiatives to help service providers understand and distinguish cultural and linguistic patterns of clients [37]. Recognizing the need for training and education in this area, ASHA has been supporting its members through several workshops, continued education sessions (CEUs), and scientific webinars [24]. ASHA's current standards and implementation procedures for certification in speech-language pathology for clinical fellows mandates supervised clinical practicum hours in working with clients from various cultural and linguistic backgrounds [34]. Some states such as Illinois and New Mexico require a bilingual certification for SLPs to work with bilingual clients. In addition, there are several multicultural constituency groups (e.g., Asian Indian Caucus, Native American Caucus, and the National Black Association for Speech, Language, and Hearing) within ASHA that function independently to promote clinical skills among SLPs who serve CLD clients.

Previous research surveys with SLPs working with CLD clients indicate that SLPs report availability and access to CLD training (both pre-service and in-service). As shown in Table 1 , the listed survey studies differed in their sample size and characteristics. Some studies were conducted in a single state while others represented nation-wide data. Studies also differed on what constituted preservice training. Despite these discrepancies, all studies endorsed the provision of graduate training on multicultural issues, a factor that impacts clinical self-efficacy. Roseberry-McKibbin and her colleagues found that SLPs who had pre-service graduate coursework experienced increased competence than their peers who had less or no coursework [21]. The initial survey study conducted by 
Roseberry-McKibbin \& Eicholtz [17] indicated that only 23\% of their survey respondents had taken coursework in working with bilingual clients. In the follow-up study, participant SLPs reported an increase in both prior relevant coursework and an increased caseload of CLD clients [21]. Those who received training in working with ELL clients reported higher clinical competence when compared to those who received less or no training. Further, participants who had taken an entire coursework on CLD practices had a higher caseload of CLD clients than their counterparts who had less or no coursework. As reported by Kohnert et al. [22], out of 104 respondents in the study, less than $50 \%$ of the SLPs had received prior training in their graduate curriculum. However, Guiberson \& Atkins [3] found that about $70 \%$ of the respondents had received training in second-language acquisition and language differences and disorders, and about $25 \%$ of the respondents were trained in assessment of CLD clients. Recent findings from Santhanam \& Parveen's study [23] indicated that $98 \%$ of the SLP participants received pre-service training and $82.8 \%$ received inservice training. These findings indicate that several graduate programs across the United States have taken efforts to educate and prepare SLPs in working with CLD clients. In-service training has been reported to be steadily increasing with the inclusion and access to workshops, continued education hours, and clinical webinars [3].

In summary, a positive trend in establishing and increasing access to education on CLD service delivery is evident. It is important to continue to support our service providers with the necessary resources and tools as we continue to witness an increase in our CLD clientele. Creating and demonstrating the connection between stakeholders including clinicians, clients, researchers, and teaching institutions is essential for continued progress. In the subsequent sections of the review, implications for stakeholders and strategies to better prepare SLPs in CLD service delivery are being addressed.

\section{Implications for stakeholders \\ Implications for graduate programs}

Several graduate programs across the nation currently provide a specialized course in working with linguistically and culturally diverse populations [38]. However, in most universities, the existing coursework does not cover all areas of CLD service delivery [3]. Current pre-service and in-service education highly focus on the following areas: second language acquisition, understanding communication patterns in other cultures, and identifying language differences versus language disorders [3,4]. Clinical education on assessment tools used for English language learners, laws associated with CLD service delivery, and use of language interpreters in treatment are topics that have received limited attention for training purposes $[3,25]$. Hammer and colleagues reported that only $25 \%$ of the SLPs working with Spanish-English children received any instruction in collaborating with interpreters [39]. Therefore, graduate-level courses should lay equal emphasis on a wide range of topics in CLD service delivery [4]. For example, the graduate program at San Jose State University provides students the opportunity to attend workshops in working with language interpreters, counseling CLD families, and language-specific training [38].

Another important consideration for graduate programs is to create practicum opportunities for students to learn and apply their skills. In addition to the master's degree requirements, some universities offer a 50-hour specialized clinical practicum for students working with CLD families [36,38]. In an effort to create more real-world opportunities, graduate programs could collaborate with local school districts and community centers that represent a large proportion of CLD individuals. Previous research indicates that SLPs strongly articulate the need for more specific and relevant coursework at the graduate level and increased real-world clinical experiences [31]. By utilizing the expertise of national and local consultants in multicultural and multilingual issues, graduate programs can help prepare their students in this area of service delivery.

In addition, with the increase in use of technology and webbased procedures, graduate programs could familiarize students to various online assessments and intervention tools that they could use with CLD clients. It is also important to constantly update the coursework on multicultural issues incorporating recent developments and changes to existing bilingual/bicultural assessments. For example, the GoldmanFristoe Test of Articulation- 3rd edition (GFTA- 3) was published recently with test items relevant to Spanish-speaking families [40].

Finally, we need more education in learning how to collaborate with language interpreters and effectively utilize their services. Use of professional language interpreters helps build client satisfaction and a better sense of self-efficacy among clinicians [41]. Langdon \& Saenz [42] suggest using a BID process while working with language interpreters. The process involves: (1) Briefing - taking time to process and plan the content for a given session; (2) Interaction - working as a team 
to directly address the concerns of the client and the family, and monitoring the interpreter's administration of given tasks, and (3) Debriefing - reviewing the process and providing a follow-up plan for the client and the family.

\section{Implications for clinicians}

Non-English-speaking families often have a strong need to use their primary language at home [43]. Federal and state laws mandate that all non-English speaking clients should be evaluated and treated in their primary language, and that assessments should be completed in the language that is most comfortable to the individuals [44]. Federal law requires that all communication between practitioners and family members with limited English proficiency should be in a language and format that they can easily understand [45]. With easier readability and comprehension of resources and available supports, a better relationship of trust is likely to build between practitioners and families.

Our assessment and intervention practices have to be individualized taking into consideration each child's linguistic and cultural factors. For example, case history forms and clinical interviews can be customized to the culture and language of the client. Further, rather than solely relying on standardized norm-referenced tests, clinicians should triangulate their assessment findings using a combination of formal and informal assessment procedures [46]. Formal norm- and criterion-referenced tests, language sample analysis, caregiver reports, and direct observations will help garner in-depth information about the client's skills and needs [47]. When a combination of approaches is used with children from non-English-speaking homes, the limitations in using a single assessment are diminished [48]. In addition, use of home videos and direct observations can be valuable sources of information in understanding cultural and linguistic practices unique to each family.

In the past decade, several speech and language assessments and diagnostic tests have been made available in languages other than English. For example, the Clinical Evaluation of Language Fundamentals ${ }^{\circledR}$ - 4 th Edition Spanish (CELF4 Spanish) [49], and the Goldman-Fristoe Test of Articulation3rd edition (GFTA- 3 Spanish) [40] have language- and culture-specific norms and testing items. In the absence of such assessment tools in the client's native language, adaptations can be used [50]. While most tests are available in Spanish, the McArthur-Bates Communication Development Inventory (CDI) is a parent questionnaire that provides information about young children's vocabulary, grammar, and use of ges- tures [51]. Adaptations of the CDI are also available in several Asian, African, Indian, and European languages.

Materials for intervention should be carefully chosen and customized for the family and client's requirements [50]. For example, in early intervention and school settings, clinicians can incorporate books, stories, and songs from children's native language and culture. We must continue to choose visual aids and pictures that are culturally sensitive and relevant. Rather than focusing on overall language exposure, clinicians could help parents identify specific communication opportunities and daily routines to focus directly on increasing vocabulary in both languages [52]. Using technology to share webbased resources in the family's primary language and facilitating online community interactions can benefit culturally and linguistically diverse families.

As service providers, we are also responsible to educate families on the myths and misconceptions about bilingual exposure. Parent-child interactions in the primary language have a broader social impact, and extend beyond the positive influence on language development [27]. Therefore, supporting families in using their primary language is one of our responsibilities. In order to build a more collaborative and positive relationship with CLD clients, Olivares \& Altarriba [53] suggest that clinicians take into account their clients' psychoemotional factors and build a trusting relationship with them. One important factor among SLPs who reported a higher sense of self-efficacy while working with CLD clients, has been the ability to relate to the clients [39]. When families can build a relationship of trust with the service providers, the collaborative environment facilitates communication [27].

Some challenges faced by CLD families include limited knowledge of speech-language and audiology services, difficulty accessing the internet, delay in referrals, and delay in finding service providers [54]. In addition, several CLD families have limited understanding of health insurance and policies [55], receive late identification and diagnosis [56], and face financial barriers to accessing services [57]. Some families have limited understanding of assessments and their purpose [32]. In such situations, SLPs must familiarize clients to the nature and purpose of different assessment tools. The lack of awareness, knowledge, availability, and access to resources and supports is exacerbated in CLD families from low socioeconomic backgrounds [55]. This scenario clearly indicates that families that belong to diverse cultural and language environments should be encouraged to advocate for their service needs. Empowering parents and caregivers by actively in- 
volving them in clinical decisions and intervention, and offering them several opportunities to engage and ask questions during sessions is essential for better clinical outcomes [28].

Service providers can also advocate for CLD families and clients while working in conjunction with other professionals. Families must be made aware that they have the right to ask for language interpreters/translators when they have difficulty communicating with their service providers [42]. Additionally, educating families on what resources exist, how to access them, and how to use them is important. We also need to familiarize family members to the steps involved in the assessment and intervention process. Uncertainties, confusions, and stressors can be prevented by providing a structure to the interaction and setting clear expectations [58]. Parents and caregivers would benefit from partnering with community agencies and non-profit organizations to build their resources and gain access to necessary information in supporting their child's communication and developmental needs. Finally, we could help create support groups and facilitate online communities for parents and caregivers who share the same linguistic and/or cultural background.

Finally, we would benefit from assessing our own knowledge and preparedness before initiating services. For example, The Cultural Competence Self-Test is a self-administered checklist that is used among physicians to help gauge their knowledge and identify areas that need improvement [59]. An adaptation of this checklist could be used to determine strengths and challenges of SLPs working with CLD clients. Clinicians should frequently update their knowledge on current research in bilingual/bicultural service delivery and use the research evidence to inform their clinical practices. Finally, it is imperative to take continued efforts in learning specific ways to actively involve CLD families in our clinical decisions, and to extend our knowledge in bilingual and bicultural service delivery.

\section{Research implications}

Most existing research studies have used a survey methodology to study the self-efficacy and perceived challenges and experiences of SLPs serving CLD clients in pediatric settings with an exception of Santhanam \& Parveen [23] who included SLPs in adult settings. Further investigations exploring self-efficacy of SLPs working in adult and geriatric settings are essential to understand if any differences exist. In addition to survey-based studies, direct observations of SLPs working with clients will provide a more in-depth understanding of persisting challenges and strategies used by service providers.
A majority of bilingual research efforts identified in this review have occurred in North America. While approximately $20 \%$ of the children in the U.S. are raised in bilingual homes (U.S. Census Bureau, 2014), about $56 \%$ of the children in Europe are bilingual [60]. Clearly, service providers around the world experience issues related to CLD service delivery. Therefore, it is important to extend our research initiatives to countries in other continents that have a larger bi-/multilingual population so we can learn and share techniques and approaches with each other. Further, a large proportion of bilingual research studies in the United States focus on Spanish-language users. It is critical that we expand our understanding of the needs of other language users (e.g., Arabic, Hindi, French, etc.).

Several focused research efforts could be taken to improve clinical self-efficacy among SLPs. We can educate service providers by investigating how language-specific variables impact our assessment and treatment practices [50]. We can conduct more studies to help us understand how developmental and acquired language disorders manifest in clients from diverse cultural and linguistic backgrounds. For example, in the field of nursing, clinical simulation techniques have been found to improve the sense of self-efficacy among clinicians [8]. Similarly, research studies aimed at creating such simulation experiences and exercises for beginning clinicians and students in communication sciences \& disorders would be helpful in preparing them to work with multicultural clients.

Most clinician-client relationships and rapport build over time [61]. Therefore, it becomes essential to conduct longitudinal research by observing SLPs interacting with their CLD clients over a period of time. This data would help understand how the clinician's sense of efficacy, assessment, and intervention decisions evolve in line with client priorities and clinical outcomes. Research needs to continue to explore some of the barriers to service delivery and access to services in rural areas, and regions that have a widespread diversity [5]. We must channel our efforts in targeting specific geographical regions of our country to ensure that resources and education in CLD service delivery is equally dissipated and made available to all, including CLD families from low socio-economic backgrounds.

\section{CONCLUSION}

In the last two decades, we have shifted our attention from merely discussing the need to actually taking efforts to in- 
crease the quality of our service delivery to clients from other linguistic and cultural backgrounds. SLPs are increasingly involved in assessing and treating CLD clients than they did in the past. Additionally, graduate programs, policy makers, and ASHA have invested more time and resources in educating SLPs to better equip themselves in serving CLD clients. Despite these promising trends, it is imperative to extend our knowledge and increase our efforts in learning innovative ways to achieve improved outcomes for the clients we serve. Factors that are barriers to bilingual service delivery still need to be addressed. In order to reach all segments of our community and extended society, we have to continue our efforts as a field to ensure uniform access and availability of supports and services to all CLD families.

\section{REFERENCES}

1. U.S. Census Bureau. American Community Survey. 2014. Retrieved from http://www.census.gov/data/tables/2013/demo/20092013-lang-tables.html

2. Ortman JM, Shin HB. Language projections: 2010 to 2020. Paper presented at the annual meetings of the American Sociological Association, Las Vegas, NV. 2011;8:20-23.

3. Guiberson M, Atkins J. Speech-language pathologists' preparation, practices, and perspectives on serving culturally and linguistically diverse children. Communication Disorders Quarterly. 2012;33:169-180.

4. Kritikos EP. Speech-language pathologists' beliefs about language assessment of bilingual/bicultural individuals. American Journal of Speech-Language Pathology. 2003;12: 73-91.

5. Kadyamusuma MR. Limitations to practicing as a bilingual SpeechLanguage Pathologist in the United States. Journal of Speech Pathology \& Therapy. 2016;1:e103.

6. American Speech-Language-Hearing Association. Directory of bilingual speech-language pathologists and audiologists 2016-17. Rockville, MD.

7. Mazhari MS. A study on the relationship between self-efficacy of clinical practice and nursing students' creativity. Journal UMP Social Sciences and Technology Management. 2015;3:Suppl. 1:317321.

8. Tuttle RE. The impact of simulation in nursing education on the self-efficacy and learner satisfaction of nursing students. (Unpublished doctoral dissertation). Capella University, USA; 2009.

9. Bandura A. Exercise of personal agency through the self-efficacy mechanism. In R. Schwarzer (Ed.), Self-efficacy: thought control of action (pp. 3-38). Washington, D.C.: Hemisphere; 1992.

10. Bandura A. Self-efficacy: toward a unifying theory of behavioral change. Psychological Review. 1977;84:191-215.

11. Bandura A. Social cognitive theory: anagentic perspective. Annual Review Psychology. 2001;52:1-26.
12. Bandura A. Self-Efficacy: The exercise of control. First Edition, (New York: Freeman company). 1997.

13. Ashton PT, Webb RB. Making a difference: Teachers' sense of efficacy and student achievement. New York, NY: Longman. 1986.

14. Stein MK, Wang MC. Teacher development and school improvement: The process of teacher change. Teaching and Teacher Education. 1988;4:171-187.

15. Gibson S, Dembo MH. Teacher efficacy: A construct validation. Journal of Educational Psychology. 1984;7:569-582.

16. Song M, Yang N. Impact on self-efficacy, self-directed learning, clinical competence on satisfaction of clinical practice among nursing students. Advanced Science and Technology Letters. 2016; 132:124-129.

17. Roseberry-McKibbin CA, Eicholtz GE. Serving limited English proficient children in schools: a national survey. Language, Speech, and Hearing Services in Schools. 1994;25:156-164.

18. Perry AR. Cultural competence in speech-language pathology: A review of where we are and where we go. Research Papers. 2012; Paper 233. Retrieved from http://opensiuc.lib.siu.edu/gs_rp/233

19. Damico JS, Damico SK. Language and social skills from a diversity perspective: considerations for the speech-language pathologist. Language, Speech, and Hearing Services in Schools. 1993;24:236243.

20. American Speech-Language-Hearing Association. ASHA 2016 schools survey: SLP caseload characteristics. Rockville, MD. 2016; Retrieved on Jan 2, 2018 from http://www.asha.org/uploadedFiles/ 2016-Schools-Survey-SLP-Caseload-Characteristics.pdf

21. Roseberry-McKibbin C, Brice A, O'Hanlon L. Serving English Language learners in public school settings: a national survey. Language, Speech, and Hearing in Schools. 2005;36:48-61.

22. Kohnert KJ, Kennedy MRT, Glaze L, Kan PF, Carney E. Breadth and depth of diversity in Minnesota: challenges to clinical competency. American Journal of Speech Language Pathology. 2003; 12:259-272.

23. Santhanam S, Parveen S. Serving linguistically diverse clients: review and research findings on changing trends in clinical self-efficacy. Presented at the Annual American Speech-Language-Hearing Association Convention, Los Angeles, California. 2017.

24. Roberts DM. The challenges of bilingual speech- language therapy: Perspectives from Speech-Language Pathologists. (Unpublished Honors Project). Syracuse University. 2008.

25. Scott M. Speech- language services for bilingual students: Relevant issues and concerns. (Unpublished senior Honors thesis). Eastern Michigan University. 2014.

26. Yu B. Issues in bilingualism and heritage language maintenance: Perspectives of minority-language mothers of children with autism spectrum disorders. American Journal of Speech-Language Pathology. 2013;22:10-24.

27. Yu B. Code- switching as a communicative resource within routine, bilingual family intervention for a child on the autism spectrum. Perspectives of the ASHA Special Interest Groups. 2016; 1(1).

28. Lau AS, Fung JJ, Ho LY, Liu LL, Gudino OG. Parent training with high-risk immigrant Chinese families: a pilot group randomized 
trial yielding practice-based evidence. Behavioral Therapy. 2011; 42(3).

29. Escarce JJ, Kapur K. Access to and quality of health care. In Tienda. M. \& Mitchell, F. (Eds). Hispanics and the Future of America. Washington, DC: Committee on transforming our common destiny (pp. 410-415). National Research Council National Academy Press. 2006.

30. Eggenberger SK, Grassley J, Restrepo E. Culturally competent nursing care for families by listening to the voices of Mexican-American women. Online Journal of Issues in Nursing. 2006;11:7.

31. Harris KP. Speech-language pathologists' professional efficacy beliefs about assessing the language skills of bilingual/bicultural/ bidialectal students. (Unpublished doctoral dissertation). University of South Florida. 2004.

32. Brice AE, Wallace SE, Brice RG. Alzheimer's Dementia From a Bilingual/Bicultural Perspective: a Case Study. Communication Disorders Quarterly, 2014;36:55-64.

33. Sanchez K, Wood C. Perceptions of disability: families from culturally and linguistically diverse backgrounds. SIG 16 Perspectives of the ASHA Special Interest Groups, 2016;1:38-46.

34. American Speech-Language-Hearing Association. 2014 Standards and implementation procedures for the certificate of clinical competence in speech-language pathology. Rockville, MD. 2014. Retrieved on Sep 21, 2017 http://www.asha.org/Certification/2014Speech-Language-Pathology-Certification-Standards/

35. Council on Academic Accreditation. Standards for accreditation of graduate education programs in audiology and speech-language pathology. 2016. Retrieved from http://caa.asha.org/wpcontent/uploads/Accreditation-Standards-for-Graduate-Programs.pdf

36. Keller-Bell Y, Scott D, Jackson S, Miller K, Gillespie RC. BridgesBond SJ. A framework for developing cultural competence in speech-language pathology: a tutorial. Journal of National Black Association for Speech-Language Hearing. 2017;9-19.

37. Saad C, Polovoy C. Differences or disorders? The ASHA Leader. 2009;14:24-25.

38. Quach W, Tsai P. Preparing future SLPs for the clinical world of cultural-linguistic diversity. SIG 14 Perspectives of the ASHA Special Interest Groups. 2017;2:82-102.

39. Hammer CS, Detwiler JS, Detwiler J, Blood GW, Qualls CD. Speech language pathologists' training and confidence in serving Spanish-English Bilingual children. Journal of Communication Disorders. 2004;37:91-108.

40. Goldman R, Fristoe M. Goldman-Fristoe Test of ArticulationThird Edition, Spanish (GFTA- 3 Spanish). San Antonio, TX. Pearson Clinical. 2017.

41. Dysart-Gale D. Clinicians and medical interpreters: negotiating culturally appropriate care for patients with limited English ability. Family \& Community Health. 2007;30:237-246.

42. Langdon HW, Saenz TI. Working with interpreters to support students who are English language learners. Perspectives of the ASHA Special Interest Groups. 2016:1:15-27.

43. Schwartz M. Family language policy: core issues of an emerging field. In Li Wei. (Ed). Applied Linguistics Review (pp. 171-192). Berlin and New York: De Gruyter Mouton. 2010.

44. Individuals with Disabilities Education Improvement Act of 2004 (IDEA), Pub. L. No. 108-446, 118 Stat. 2647. 2004.

45. Exec. Order No. 13,166, 3 C.F.R. Retrieved on Sep 1, 2017 from https://www.lep.gov/13166/eo13166.html. 2000.

46. Kohnert K, Medina A. Bilingual children and communication disorders: a 30-year research retrospective. Seminars in Speech and Language. 2009;30:219-233.

47. Santhanam S, Hewitt LE. Evidence-based assessment and autism spectrum disorders: a scoping review. Evidence-Based Communication Assessment and Intervention. 2015:9:140-181.

48. De Lamo White C, Jin L. Evaluation of speech and language assessment approaches with bilingual children. International Journal of Language and Communication Disorders. 2011;46:613-627.

49. Wiig EH, Secord WA, Semel E. Clinical Evaluation of Language Fundamentals Preschool, Spanish Edition (2nd ed.). (CELF- P2 Spanish). San Antonio, TX. Pearson Assessments. 2009.

50. Goral M, Conner PS. Language disorders in multilingual and multicultural populations. Annual Review of Applied Linguistics. 2013; 33:128-161.

51. Fenson L, Dale PS, Reznick JS, Thal D, Bates E, Hartung JP, et al. The MacAurthur Communicative Development Inventories (CDI). Baltimore, MD: Brookes. 1993.

52. Hambly C, Fombonne E. Factors influencing bilingual expressive vocabulary size in children with autism spectrum disorders. Research in Autism Spectrum Disorders. 2014;8:1079-1089.

53. Olivares I, Altarriba J. Mental health considerations for speechlanguage services with bilingual Spanish-English speakers. Seminars in Speech and Language. 2009;30:153-161.

54. Mahendra N, Schoneman K, Engineer N. Barriers influencing minority clients' access to speech language pathology services. Presented at the Annual American Speech-Language-Hearing Association Convention, New Orleans, LA. 2009.

55. Tek S, Landa RJ. Differences in autism symptoms between minority and non-minority toddlers. Journal of Autism and Developmental Disorders. 2012;42:1967-1973.

56. Gourdine RM, Baffour TD, Teasley M. Autism and the African American Community. Social Work in Public Health. 2011;26:454470.

57. Baldwin DM. Disparities in health and health care: focusing efforts to eliminate unequal burdens. Online Journal of Issues in Nursing. 2003;8:113-122.

58. Westby C. Considerations in working successfully with culturally/ linguistically diverse families in assessment and intervention of communication disorders. Seminars in Speech and Language. 2009;30:279-289.

59. Goode TD. Self-assessment developed by Tawara D. Goode. Adapted with permission from Promoting Cultural Competence and Cultural Diversity in Early Intervention and Early Childhood Settings and Promoting Cultural Competence and Cultural Diversity for Personnel Providing Services and Supports to Children With Special Health Care Needs and Their Families (June 1989; lat- 
est revision July 2000). Georgetown University Child Development Center-UAP. 1989.

60. Marian V, Shook A. The cognitive benefits of being bilingual. Ce- rebrum: The Dana Forum on Brain Science. 2012;13:1-12.

61. Duchan JF, Kovarsky D. Rapport and relationships in clinical interactions. Topics in Language Disorders. 2011;31:297-299. 